\title{
PENERAPAN PERLINDUNGAN HUKUM TERHADAP HAK CUTI HAID \\ BERDASARKAN PASAL 81 AYAT (1) UNDANG-UNDANG NO. 13 TAHUN 2003 \\ TENTANG KETENAGAKERJAAN
}

\author{
Oleh : \\ Windi Arista,SH.,MH \\ (Dosen Tetap Sekolah Tinggi Ilmu Hukum Sumpah Pemuda Palembang) \\ Email : arista.windi@yahoo.co.id
}

\begin{abstract}
ABSTRAK
Secara kodrat pekerja perempuan memang memiliki perbedaan yang merupakan pemberian Tuhan Yang Maha Esa yang bersifat permanen dan tidak dapat diubah. Berdasarkan kodrat itulah kemudian timbul hak-hak istimewa sebagaimana yang disebutkan dalam Undang-Undang Nomor 13 Tahun 2003 yaitu hak reproduksi seperti cuti haid, cuti hamil, cuti melahirkan, menyusui, dan lain sebagainya, dalam prakteknya hak-hak tersebut seringkali tidak diberikan dan pemegang hak hanya pasrah tanpa bisa berbuat apapun.

Penerapan hak cuti haid tersebut bukan berupa pemberian cuti yang khusus diberikan kepada pekerja perempuan setiap bulannya,tetapi berupa ijin sakit dan tetap digaji bagi tenaga kerja tetap. Berbeda dengan pekerja tetap penerapan hak cuti haid ini tidak diterapkan terhadap tenaga kerja yang tidak tetap yang pemberian upahnya berupa upah harian. Jadi, jika tidak bekerja maka tidak digaji, sehingga dapat disimpulkan perusahaan tidak memberikan hak pada pekerjatidak tepat untuk cuti haid. Hal ini dikarenakan pekerja harian tidak memiliki kontrak kerja dengan perusahaan sehingga hak-haknya pun dibatasi.
\end{abstract}

Kata Kunci : Cuti Haid, Perlindungan Hukum

\section{ABSTRACT}

By nature, women workers do have a difference, which is a gift from God Almighty which is permanent and irreversible. Based on this nature, special rights arose as stated in Law Number 13 of 2003, namely reproductive rights such as menstrual leave, maternity leave, maternity leave, breastfeeding, etc., in practice these rights are often not granted and holders right just surrender without being able to do anything.

The application of the right to menstrual leave is not in the form of giving leave specifically given to female workers every month, but in the form of sick leave and salary for permanent workers. In contrast to permanent workers, the application of the right to menstrual leave does not apply to temporary workers whose wages are daily wages. So, if you don't work, you don't get paid, so it can 
be concluded that the company doesn't give workers the right to leave menstruation. This is because daily workers do not have a work contract with the company so that their rights are limited.

Keywords: menstrual leave, legal protection

\section{A. Latar Belakang}

Negara Indonesia pada saat ini sedang melaksanakan pembangunan disegala bidang.Pembangunan ini meliputi juga pembangunan ketenagakerjaan.Pembangunan ketenagakerjaan merupakan bagian integral dari pembangunan nasional berdasarkan Pancasila dan Undang Undang Dasar Negara RepublikIndonesia Tahun 1945, pembangunan ketenagakerjaan ini di laksanakan dalam rangka pembangunan manusia Indonesia seutuhnya dan pembangunan masyarakat Indonesia seluruhnya untuk meningkatkan harkat, martabat, dan harga diri tenagakerja guna mewujudkan masyarakat sejahtera, adil, makmur, dan merata baiksecara materiil maupun spirituil. ${ }^{1}$

Salah satu persoalan yang muncul dalam pembangunan ketenagakerjaan yaitu adanya pelanggaran terhadap perlindungan hukum hak-hak perempuan yang bekerja di suatu perusahaan salah satunya hak cuti haid.

Di dalam Pasal 6 Undang-undang Nomor 13 Tahun 2003 ditentukan bahwa "Setiap pekerja/buruh berhak memperoleh perlakuan yang sama tanpa diskriminasi dari pengusaha." Ketentuan Pasal 6 Undang-undang Nomor 13 Tahun 2003 ini semakin memperjelas ketentuan Pasal 5 Undang-undang Nomor 13 Tahun 2003 bahwa tidak ada perbedaan antara laki-laki dan perempuan dalam dunia kerja.Berdasarkan dari ketentuan undang-undang yang melarang adanya diskriminasi antara perempuan dan laki-laki dalam dunia kerja (das sollen), maka seharusnya di dalam kenyataannya perempuan yang bekerja memang benar-benar diperlakukan tanpa adanya diskriminasi dengan laki-laki. Akan tetapi di dalam kenyataannya (das sein) sering terjadi diskriminasi antara laki-laki dan perempuan dalam banyak aspek dari pekerjaan, misalnya dari segi gaji, tunjangan, jenjang karier, dan lain-lain.

${ }^{1}$ Lihat Penjelasan Undang - Undang Nomor 13 Tahun 2003 Tentang Ketenagakerjaan 
Selain itu secara kodrat pekerja perempuan memang memiliki perbedaan yang merupakan pemberian Tuhan Yang Maha Esa yang bersifat permanen dan tidak dapat diubah. Berdasarkan kodrat itulah kemudian timbul hak-hak istimewa sebagaimana yang disebutkan dalam Undang-Undang Nomor 13 Tahun 2003 yaitu hak reproduksi seperti cuti haid, cuti hamil, cuti melahirkan, menyusui, dan lain sebagainya, dalam prakteknya hak-hak tersebut seringkali tidak diberikan dan pemegang hak hanya pasrah tanpa bisa berbuat apapun. Pengertian hak dapat dipakai dalam arti kekebalan terhadap kekuasaan orang lain. ${ }^{2}$ Sedangkan haid yaitu tentang peristiwa psikologis dan siklus pada wanita di masa reproduksi dengan keluarnya darah dari rahim sebagai akibat pelepasan selaput lender rahim. ${ }^{3}$

Secara umum diketahui, meski sudah diakui dalam peraturan perundangan, tidak mudah mendapatkan hak cuti haid. Perempuan dipaksa untuk memperlihatkan surat keterangan dokter bahwa dirinya haid dan jenisjenis pemeriksaan lainnya. Umum diketahui pula, jika perempuan mengambil hak cuti haid, akan dituduh memanfaatkannya masa cutinya untuk keperluan lain, semisal berlibur, sekilas alasan tersebut tampak benar.

Berdasarkan hal-hal tersebut, maka peneliti tertarik untuk membuat penelitian dengan judul Penerapan Perlindungan Hukum Terhadap Perempuan Dalam Hal Cuti Haid Berdasarkan Pasal 81 Ayat (1) Undang-Undang No. 13 Tahun 2003 Tentang Ketenagakerjaan.

\section{B. Permasalahan}

Adapun permasalahan yang akan penuli ambil dalam tulisan ini adalah mengenai :

1. Bagaimana Penerapan Perlindungan Hukum Terhadap Hal Cuti Haid Berdasarkan Pasal 81 Ayat (1) Undang-Undang No. 13 Tahun 2003 Tentang Ketenagakerjaan?

\footnotetext{
${ }^{2}$ Muh. Shiddiq Tgk.Armia, Perkembangan Pemikiran Dalam Ilmu Hukum,PT.Pradnya Paramita ,Jakarta,2003,hlm.47

${ }^{3}$ C.S.T Kansil, Pengantar Ilmu Hukum dan Tata Hukum Indonesia,: Balai Pustaka, Jakarta 1989, hlm.311
} 
2. Apakah faktor penyebab tidak terpenuhnya hak pekerja perempuan?

\section{Pembahasan}

Perlindungan Hukum Timbul karena adanya suatu hubungan hukum. Hubungan hukum merupakan interaksi antara subjek hukum yang mempunyai relevansi hukum atau akibat hukum yaitu timbulnya hak dan kewajiban. ${ }^{4}$ Hubungan hukum merupakan interaksi antara subjek hukum yang mempunyai relevansi hukum atau akibat hukum yaitu timbulnya hak dan kewajiban. ${ }^{5}$

Menurut Muchsin, perlindungan hukum merupakan suatu hal yangmelindungi subyek-subyek hukum melaluiperaturan perundang-undangan yangberlaku dan dipaksakan pelaksanaannya dengan suatu sanksi.

Perlindungan hukum dapat dibedakan menjadi dua, yaitu:

a. Perlindungan HukumPreventif,perlindungan yang diberikan oleh pemerintahdengan tujuan untuk mencegahsebelum terjadinya pelanggaran. Hal ini terdapat dalam peraturan perundang-undangan dengan maksud untukmencegah suatu pelanggaran serta memberikan rambu-rambu atau batasan-batasan dalam melakukan suatu kewajiban.

b. Perlindungan Hukum Represif,perlindungan akhir berupa sanksi seperti denda,penjara, dan hukuman tambahan yang diberikan apabila sudah terjadi sengketaatau telah dilakukan suatu pelanggaran ${ }^{6}$

Pengaturan perlindungan hukum mengenai masalah cuti haid tenaga kerja wanita diatur di dalam Pasal 81 Undang-Undang Nomor 13 Tahun 2003 tentang Ketenagakerjaan yang berbunyi :

(1). Pekerja/buruh perempuan yang dalam masa haid merasakan sakit danmemberitahukan kepada pengusaha, tidak wajib bekerja pada haripertama dan kedua pada waktu haid

(2). Ketetuan mana sebagaimana dimaksud dalam ayat(1) diatur dalamperjanjian kerja, peraturan perusahaan, atau perjanjian kerja bersama.

Pasal 83 Undang-Undang Nomor 13 Tahun 2003 tentang Ketenagakerjaanyang berbunyi :"Pekerja/buruh perempuan yang anaknya

\footnotetext{
${ }^{4}$ Asri Wijayanti, Hukum Ketenagakerjaan Pasca Reformasi, Sinar Grafika, Jakarta, 2010, hlm..6

${ }^{5}$ Soeroso, Penghantar Ilmu Hukum, Cetak Kedelapan, Sinar Grafik, Jakarta, 2006, hlm.49

${ }^{6}$ Harjono,Dasar-Dasar PerlindunganTenaga Kerja,CV.Makna jaya, Jakarta 2003,hlm. 270
} 
masih menyusui diberikesempatan sepatutnya untuk menyusui anaknya jika hal itu harus dilakukanselama waktu kerja."

Pasal 84 Undang-Undang Nomor 13 Tahun 2003 tentang Ketenagakerjaanyang berbunyi :"Setiap pekerja/buruh yang menggunakan hak waktu istirahat sebagaimanadimaksud dalam Pasal 79 ayat (2) huruf a,b,c, dan d, Pasal 80, dan Pasal 82,berhak mendapat upah penuh.”

Selain berdasarkan pada Undang-Undang Nomor 13 Tahun 2003 tentang Ketenagakerjaan, pelaksanan perlindungan hukum hak cuti haid juga mengacu pada Peraturan Pemerintah Republik Indonesia Nomor 78 Tahun 2015 Tentang Pengupahan yaitu ketentuan Pasal 24 Ayat (3) huruf b yang mengatur: "Pekerja/buruh perempuan yang sakit pada hari pertama dan kedua masa haidnya sehingga tidak dapat melakukan pekerjaan".

Di dalam ketentuan Pasal 1 Angka (1) Undang-Undang Nomor 39 Tahun 1999 tentang Hak Asasi Manusia, memberikan rumusan tentang pengertian Hak Asasi Manusia sebagi berikut:

"Seperangkat hak yang melekat pada hakikatnya dan keberadaan manusia sebagai makhluk Tuhan Yang Maha Esa dan merupakan anugerah-Nya yang wajib dihormati, dijunjung tinggi dan dilindungi oleh Negara, hukum, pemerintah, dan setiap orang demi kehormatan serta perlindungan harkat dan martabat manusia".

Berdasarkan ketentuan-ketentuan yang disebutkan d iatas bahwa pemerintah memberikan perlindungan hukum bagi pekerja perempuan mengenai hak cuti haid. Perlindungan pekerja dapat dilakukan dengan jalan memberikan tuntunan, maupun dengan jalan meningkatkan pengakuan hakhak asasi manusia, perlindungan fisik dan teknis, serta social ekonomi melalui norma yang berlaku dalam lingkungan kerja. ${ }^{7}$ Sehingga perusahan wajib memberikan hak cuti haid bagi pekerja perempuannya. Karena haid merupakan hak kodratiyang wajib dialami oleh perempuan sebelum

${ }^{7}$ Zaeni Asyhadie, Hukum Kerja (Hukum Ketenagakerjaan bidang Hubungan Kerja), PT. Rja Grafindo Persada, Jakarta, 2007, hlm.58 
menginjak masa menopause, namun dalam prakteknya masih banyak perusahaan yang tidak menerapkan aturan tersebut.

Berdasarkan pengamatan penulis di lapangan penerapan hak cuti haid tersebut bukan berupa pemberian cuti yang khusus diberikan kepada pekerja perempuan setiap bulannya,tetapi berupa ijin sakit dan tetap digaji bagi tenaga kerja tetap. Berbeda dengan pekerja tetap penerapan hak cuti haid ini tidak diterapkan terhadap tenaga kerja yang tidak tetap yang pemberian upahnya berupa upah harian. Jadi, jika tidak bekerja maka tidak digaji, sehingga dapat disimpulkan perusahaan tidak memberikan hak pada pekerja tidak tepat untuk cuti haid. Hal ini dikarenakan pekerja harian tidak memiliki kontrak kerja dengan perusahaan sehingga hak-haknya pun dibatasi.

Sistem pemberian cuti haid ini diberikan apabila pekerja yang hendak cuti haid menyertakan surat keterangan dari dokter. Namun cuti haid tersebut hanya diberikan sebanyak 2 hari saja, jika pekerjanya cuti melebih dua hari maka akan dipotong liburnya dalam satu minggu dan atau cuti tahunan yang dimiliki oleh pekerjanya tersebut.Kemudian jika dalam ijin sakit ini pekerja tidak dapat menyertakan surat keterangan dokter maka libur dan cuti yang dimiliki oleh pekerjayang bersangkutan digunakan sebagi penggantinya. Hal ini dilakukan untuk menghindari kecemburuan sosial antar pekerjakhususnya pekerjalaki-laki. Serta kerugian yang dapat ditimbulkan seperti, pekerjaan yang terbengkalai akibat berkurangnya pekerjayang bekerja dan menghindari kecurangan pekerja yang berniat untuk bolos bekerja dengan adanya cuti haid tersebut.

\section{Faktor penyebab tidak terpenuhnya hak pekerja perempuan}

Keberadaan perempuan yang bekerja tidak dapat dipungkiri turut membantu perekonomian negara. Namun hal ini tidak dapat dielakkan bahwa pekerja perempuan memiliki peran ganda, yaitu sebagai tenaga kerja yang harus dilindungi hak-haknya dan juga berperan sebagai ibu rumah tangga yang harus dilindungi fungsi reproduksinya. Oleh karena itu, pekerja perempuan perlu mendapat perlindungan khusus agar fungsi reproduksinya tidak terganggu. 
Dengan jumlah yang cukup besar, pekerja perempuan mempunyai hak yang sama tanpa diskriminasi dalam pekerjaan agar tetap eksis untuk berpartisipasi dalam mengisi pembangunan. Pekerja perempuan bekerja hampir di semua sektor, baik sebagai tenaga manajerial, profesional, teknis, administratif sampai ke buruh maupun menjadi wiraswasta. Masih ada kecenderungan untuk mempekerjakan perempuan di sektor pertanian dan pelayanan jasa. Sebagian besar perempuan bekerja di sektor informal yang termasuk underserved population karena populasi pekerja tidak terlindung oleh hukum maupun dalam mendapatkan pelayanan kesehatan secara memadai.

Dalam Konvensi Penghapusan Segala Bentuk Diskriminasi tehadap Perempuan beberapa hak pekerja perempuan adalah sebagai berikut :

1. Hak untuk bekerja sebagai hak asasi manusia.

2. Hak atas kesempatan kerja yang sama, termasuk penerapan criteria seleksi yang sama dalam penerimaan pegawai.

3. Hak untuk memilih dengan bebas profesi dan pekerjaan, hak untuk promosi, jaminan pekerjaan dan semua tunjangan serta fasilitas kerja, hak untuk memperoleh latihan kejuruan dan latihan ulang termasuk masa kerja sebagai magang.

4. Hak untuk menerima upah yang sama, termasuk tunjangantunjangan, baik untuk perlakuan yang sama sehubungan dengan pekerjaan dengan nilai yang sama maupun persamaan perlakuan dalam penilaian kualitas pekerjaan.

5. Hak atas jaminan sosial, khususnya dalam hal pensiun, pengangguran, sakit, cacat, lanjut usia, serta lain-lain ketidakmampuan untuk $1 / 2$ bekerja, hak atas masa cuti yang dibayar.

6. Hak atas perlindungan kesehatan dan keselamatan kerja, termasuk usaha perlindungan terhadap fungsi melanjutkan keturunan. ${ }^{8}$

Namun dalam prakteknya hak-hak tersebut seringkali tidak diberikan dan pemegang hak hanya pasrah tanpa bisa berbuat apapun. Pengertian hak adalah sesuatu kekuatan yang diatur oleh hukum dan kekuasaan berdasarkan kesusilaan (moral) dan tidak hanya kekuatan fisik saja. ${ }^{9}$ Adapun Faktor-Faktor

\footnotetext{
${ }^{8}$ Ardiyan. Wanita Pekerja, antara Diskriminasi dalam Lingkungan Kerja dan Tanggung Jawab terhadapRumahTangga, Vol. 4, No.2.,Politeknik Negeri Sriwijaya, Palembang,2012.

${ }^{9}$ R.Soeroso, Op, cit, hlm.275
} 
Yang Menyebabkan Tidak Terpenuhnya Hak-Hak Tenaga Kerja Wanita menurut Khotimah adalah :

a. Tingkat pendidikan yang rendah

b. Minimnya pengetahuan pekerja perempuan akan hak yang dimilikinya

c. Kurangnya sosialisasi dari pihak yang perusahaan atau pemerintah atas hak pekerja perempuan membuat pelaksanaan pemenuhan hak pekerja perempuan tidak terlaksana dengan baik.

d. Pengusaha kurang memahami peraturan perundang-undangan yang berlaku ${ }^{10}$

D. Kesimpulan

1. Penerapan hak cuti haid tersebut bukan berupa pemberian cuti yang khusus diberikan kepada pekerja perempuan setiap bulannya,tetapi berupa ijin sakit dan tetap digaji bagi tenaga kerja tetap. Berbeda dengan pekerja tetap penerapan hak cuti haid ini tidak diterapkan terhadap tenaga kerja yang tidak tetap yang pemberian upahnya berupa upah harian. Jadi, jika tidak bekerja maka tidak digaji, sehingga dapat disimpulkan perusahaan tidak memberikan hak pada pekerja tidak tepat untuk cuti haid. Hal ini dikarenakan pekerja harian tidak memiliki kontrak kerja dengan perusahaan sehingga hak-haknya pun dibatasi.

2. Faktor-Faktor Yang Menyebabkan Tidak Terpenuhnya Hak-Hak Tenaga Kerja Wanita menurut Khotimah adalah :

a. Tingkat pendidikan yang rendah

b. Minimnya pengetahuan pekerja perempuan akan hak yang dimilikinya

c. Kurangnya sosialisasi dari pihak yang perusahaan atau pemerintah atas hak pekerja perempuan membuat pelaksanaan pemenuhan hak pekerja perempuan tidak terlaksana dengan baik.

d. Pengusaha kurang memahami peraturan perundang-undangan yang berlaku

${ }^{10}$ Khotimah K. Diskriminasi Gender terhadap Perempuan dalam Sektor Pekerjaan., Vol. 4, No. 1STAIN ,Purwokerto,2009. 


\section{DAFTAR PUSTAKA}

Ardiyan. Wanita Pekerja, antara Diskriminasi dalam Lingkungan Kerja dan Tanggung Jawab terhadap RumahTangga, Vol. 4, No.2.,Politeknik Negeri Sriwijaya, Palembang,2012.

Asri Wijayanti, Hukum Ketenagakerjaan Pasca Reformasi, Sinar Grafika, Jakarta, 2010

C.S.T Kansil, Pengantar Ilmu Hukum dan Tata Hukum Indonesia,: Balai Pustaka, Jakarta 1989

Harjono,Dasar-Dasar PerlindunganTenaga Kerja,CV.Makna jaya, Jakarta 2003

Khotimah K. Diskriminasi Gender terhadap Perempuan dalam Sektor Pekerjaan., Vol. 4, No. 1STAIN ,Purwokerto,2009.

Muh. Shiddiq Tgk.Armia, Perkembangan Pemikiran Dalam Ilmu Hukum,PT.Pradnya Paramita ,Jakarta,2003

Soeroso, Penghantar Ilmu Hukum, Cetak Kedelapan, Sinar Grafik, Jakarta, 2006

Zaeni Asyhadie, Hukum Kerja (Hukum Ketenagakerjaan bidang Hubungan Kerja), PT. Rja Grafindo Persada, Jakarta, 2007, hlm.58 